\title{
The role of physical activity in preventing obesity in midlife women
}

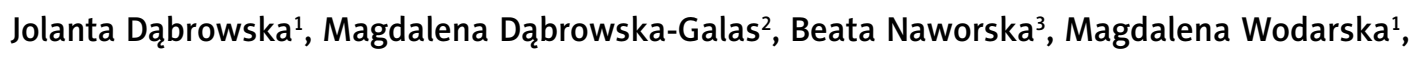 \\ Ryszard Plinta ${ }^{4}$
}

${ }^{1}$ Department of Kinesitherapy and Special Methods, School of Health Sciences in Katowice, Medical University of Silesia, Katowice, Poland

${ }^{2}$ Department of Sports Medicine and Physiology of Physical Effort, School of Health Sciences in Katowice, Medical University of Silesia, Katowice, Poland

${ }^{3}$ Department of Gynaecology and Obstetrics, School of Health Sciences in Katowice, Medical University of Silesia, Katowice, Poland ${ }^{4}$ Department of Adapted Physical Activity and Sport, School of Health Sciences in Katowice, Medical University of Silesia, Katowice, Poland

\begin{abstract}
Introduction: Obesity is one of the most common nutrition-related disorders worldwide and one of the major health problems in menopausal women, which significantly worsens the quality of life and can lead to severe diseases or even premature death. The aim of the study was to evaluate the relation between physical activity in different domains undertaken by menopausal women while performing daily activities and their body mass index (BMI).

Material and methods: The study was conducted on a random sample of 400 healthy Polish women aged 45-55. The questionnaire contained questions concerning the respondents' socio-economic status, medical history and the long format of the International Physical Activity Questionnaire was used.

Results: Fifty-one percent (50.6\%) of women had normal body mass, $43.75 \%$ of respondents were overweighed and $5.65 \%$ of women were obese. A moderate physical activity level was presented by most midlife women in domestic and garden domain, active transportation and leisure time. Pearson's correlation showed that such factors as age, education and physical activity level in different domains have a significant correlation with BMI.

Conclusions: Most respondents presented a moderate physical activity level in all domains except work, where the respondents had a high physical activity (PA) level. A high PA level especially at work $(r=-0.5788)$ and during leisure time $(r=-0.5175)$ strongly correlate with lower BMI.
\end{abstract}

Key words: motor activity, obesity, IPAQ, menopause, women.

\section{Introduction}

Obesity is one of the most common nutrition-related disorders worldwide and a major health problem in menopausal women. It significantly worsens the quality of life (QoL) and can lead to severe diseases or even premature death. It is a major risk factor for cardiovascular disease, coronary heart disease, stroke, hypertension, osteoarthritis and diabetes mellitus [1]. Longitudinal studies show that the direct correlation between obesity and fatal cardiovascular disease is the strongest in women with very high intra-abdominal fat [2].

A change of lifestyle can help reduce body mass. Regular physical activity (PA) is known to bring mental and physical benefits; by contrast, inactivity and sedentary lifestyle pose immediate health risks [3]. Climacteric women undergo various physical, social and psychological changes which affect their QoL $[4,5]$. The menopause is a time of vasomotor, urogenital and mental changes in women. Approximately $86 \%$ of menopausal females suffer from hot flashes; other symptoms include joint pains, fatigue, depression, anxiety, vaginal dryness and other sexual problems [6, 7].

The menopausal status is also a predictor of cardiovascular disease (CVD) - the main cause of mortality in climacteric women [8]. Cardiovascular disease remains the most common cause of deaths worldwide. Each year nearly half of all the deaths in Europe (over 4.3 million, 48\%) and in the European Union (over 2.0 million, $42 \%$ ) are caused by CVD [9]. Heart disease is also the leading cause of deaths in women in the United States (292,188 deaths in 2009) [10]. Three in four menopausal women are overweight or obese, which, combined with a low level of PA, contributes to an increased risk

Corresponding author: Jolanta Dąbrowska, Department of Kinesitherapy and Special Methods, School of Health Sciences in Katowice, Medical University of Silesia, 12 Medyków St., 40-752 Katowice-Ligota, e-mail: dabrowska_reh@wp.pl

To cite this article: Dąbrowska J, Dąbrowska-Galas M, Naworska B, Wodarska M, Plinta R. The role of physical activity in preventing obesity in midlife women. Prz Menopauzalny 2015; 14: 13-19.

Submitted: 29.04.2014; Accepted: 8.12.2014. 
of CVD [10, 11]. Despite the lower level of estrogens during the menopause, PA increases the level of endorphins. It also helps to manage the body mass. Physically active climacteric women have been shown to develop fewer vasomotor symptoms, experience fewer mood changes, and suffer less from muscle pain and sleep problems $[5,12,13]$. Regular PA should be recommended to all perimenopausal women in order to improve their QoL, alleviate climacteric symptoms and reduce the risk of breast cancer $[5,14]$.

The American College of Sports Medicine (ACSM) and the American Heart Association (AHA) provide general PA recommendations to improve health and wellness. The American College of Sports Medicine and AHA guidelines focus on 30 minutes of moderate-intensity PA five times a week or 20 minutes of vigorous-intensity PA three times a week [15]. These are general recommendations aiming to improve the health and cardiorespiratory fitness of inactive people. Individual PA recommendations should be age- and body mass-specific. Nevertheless, even following the general recommendations, the QoL of menopausal women improved significantly. The assessment of PA levels in different domains in women aged $45-55$ showed that $16.95 \%$ of the respondents were very active in their leisure time, $25.61 \%$ were moderately active and $9.52 \%$ were sedentary [13]. Moderate or high levels of PA during the menopause correlated with better general QoL, whilst low PA levels - with weight gain, increased climacteric symptoms and worse QoL $[15,16]$. Moderate PA improved the well-being and QoL also in postmenopausal females [17].

Physical activity is often associated with leisure time. Free-time exercise, such as yoga, during the menopause can be an alternative therapy for the management of climacteric symptoms as it may help reduce insomnia, alleviate menopausal symptoms and improve the QoL in postmenopausal women [18]. Leisure time PA has a positive effect on QoL in climacteric women, while domestic and transportation PA is inversely related to QoL [18]. In a randomized study conducted on 336 menopausal women in Poland, the absence of climacteric symptoms was observed mainly in women with moderate PA at work, during transportation, at home and during leisure time. High job-related and leisure-related PA enhances the quality of sexual functioning, while low levels of PA related to work, transportation, housework and leisure correlate with reduced sexual functioning in women aged 45-49 [13]. Menopausal females have slower metabolism and tend to exercise less, which can result in weight gain. The influence of PA on QoL depends on exercise intensity and domain.

Physical activity guidelines for menopausal women usually concern leisure time. However, whilst the impact of leisure-time PA is well established, little is known about the effect of PA related to daily activi- ties such as work, transportation and housework. Inactive women either do not have the time to exercise in their leisure time or their motivation is insufficient. Therefore, the PA levels in other domains, such as work, home or transportation should be assessed and possibly increased. One of the most highly recommended questionnaires used to evaluate the PA level in specific domains is the long format of the International Physical Activity Questionnaire (IPAQ) [19-21].

The menopause often triggers changes in body mass and body composition. Women gain weight, particularly in the abdominal area, which causes numerous health problems [12]. This may be prevented by regular PA. Although PA is mainly associated with leisure time, in our study, we hypothesized that PA relating to daily activities may also reduce BMI.

The aim of this study was to determine the relation between BMI in menopausal women and their PA level in daily activities in different domains.

\section{Material and methods}

The study was conducted on a random sample of 400 healthy Polish women aged 45-55. The inclusion criteria were: age from 45 to 55 years and written consent to participate in the study. The date of menopause was defined retrospectively following 12 months of amenorrhea. The exclusion criteria were: systemic disease (e.g. arterial hypertension, coronary heart disease, diabetes, cancer) and depression (past or present). Sixty-four respondents did not meet the inclusion criteria and were excluded from the analysis. The study was approved by the Bioethical Commission of the Medical University in Katowice in Poland (NN-6501-151/07).

The research tool was a two-part anonymous selfreport questionnaire. The first part concerned the respondents' socio-economic status (e.g. age, education, occupation, material status, income, etc.) as well as medical history and basic gynecological and obstetric history (e.g. obstetric and gynecological conditions, examinations and operations, hormone therapy), general health condition, and consumption of stimulants (alcohol, cigarettes, etc.). The second part comprised the IPAQ, long format $[1,20,21]$ and referred to the previous 7 days of PA. The minimum PA time taken into account was 10 minutes and any report of PA shorter than 10 minutes was re-coded to 0 minutes. According to the IPAQ scoring protocol, the average MET (metabolic equivalent) score is defined for each type of activity in different domains (Table I) [20].

International Physical Activity Questionnaire scores were expressed as MET - $\mathrm{min} /$ week = average MET level $\times$ minutes of PA $\times$ number of PA sessions per week. Based on the diagnostic criteria, the respondents were assigned into one of three groups: with low, moderate or high level of PA [20]. 
Tab. I. Average metabolic equivalent (MET) score for each International Physical Activity Questionnaire (IPAQ) domain

\begin{tabular}{lclc}
\hline Work Domain & & Transportation Domain & O MET \\
\hline Walking & 3.3 MET & Car & 3.3 MET \\
\hline Moderate PA level & 4 MET & Walking & 6 MET \\
\hline Vigorous PA level & 8 MET & Cycle & 3.3 MET \\
\hline Domestic and Garden Domain & & Leisure-time Domain & 4 MET \\
\hline Walking & 3.3 MET & Walking & 8 MET \\
\hline Moderate PA level & 4 MET & Moderate PA level & Vigorous PA level \\
\hline Vigorous PA level & 5.5 MET & M
\end{tabular}

According to IPAQ Scoring Protocol [43]

PA - physical activity

The body mass index $\left(\mathrm{BMI}=\right.$ body $\mathrm{mass} /$ height $\left.^{2}\right)$ was calculated based on the self-reported body mass and height and was classified as follows:

- less than 18.5 - underweight,

- 18.5 to 25.0 - normal body mass,

- 25.0 to 30.0 - overweight,

- 30.0 or more - obese [22].

\section{Statistical analysis}

The Shapiro-Wilk test was used to verify data normality. $T$-tests were used to compare differences in BMI and PA levels in different domains (work, transportation, domestic and garden, leisure time). For BMI subscales, Pearson's correlation coefficients were calculated to assess the association between changes in BMI and demographic factors (age, material status, education, marital status, place of living) and PA levels in different domains. Values of $p<0.05$ were considered significant. All analyses were performed with STATISTICA software version 10 .

\section{Results}

The mean age of the study participants was 50.56 \pm 2.33 and the majority (74.11\%) lived in big cities (over 100000 inhabitants). The respondents were assigned into one of two marital status categories: married/living with a partner (88.99\%) or single $(11.01 \%)$. Seventeen percent $(16.96 \%)$ of the subjects were educated to a primary level, $44.05 \%$ to a secondary level and $38.99 \%$ to a tertiary level. The financial status of the participants was categorized into 'poor', 'good' or 'very good'. Twenty-two percent $(22.32 \%)$ of the respondents declared a 'poor' financial status. The respondents were also divided into three body mass groups: normal (50.6\%), overweight (43.75\%) and obese (5.65\%), as indicated by their BMI.

Most women presented moderate PA levels in all four analyzed PA domains (work: $43.45 \%$, active transportation: $52.68 \%$, domestic and garden: $51.49 \%$, leisure-time: $44.35 \%$ ). A high PA level was reported by $25.3 \%$ of the respondents in the work domain, $23.21 \%$ in the garden domain and $19.94 \%$ in the leisure-time domain. No cases of high PA level were observed in the active transportation domain (Table II).

The respondents were also categorized into current smokers (20.83\%) and non-smokers (79.17\%). Ninetythree percent (93.15\%) drank coffee and $22.11 \%$ consumed alcohol. The majority of the participants (98.22\%) were employed.

Thirteen percent $(13.10 \%)$ of women had regular menstrual cycles, $38.69 \%$ irregular menstrual cycles and $48.21 \%$ were postmenopausal. Fourteen percent (14.29\%) of the respondents had undergone hysterectomy and $19.45 \%$ used hormone therapy (HT). Statistical analysis showed that significantly more women with normal BMI reported high PA ( $p<0.01)$. The PA level decreased with an increase in $B M I$ in each PA domain. Many overweight women presented a moderate PA level, particularly in the domestic and garden domain, whilst no obese females were found in the high PA group (Table III). Education correlated negatively with BMI $(r=-0.2686, p<0.01)$ - higher education levels correlated with lower BMI values. Also the PA level showed a negative correlation with BMI. The higher the PA level in any of the domains, the lower the BMI in the studied women: work domain $(r=-0.5788$, $p<0.01)$, transportation domain $(r=-0.2319, p<0.01)$, domestic and gardening domain $(r=-0.4057, p<0.01)$ and leisure time domain $(r=-0.5175, p<0.01)$, the lower BMI in midlife woman (Table IV).

\section{Discussion}

The aim of this study was to assess $\mathrm{BMI}$ and the level of PA in different domains in midlife women in order to establish a PA level facilitating the reduction of obesity. The obtained results showed an adequate PA level among the studied females, with most respondents reporting a moderate PA level in most domains.

Sedentary lifestyle is becoming a large-scale problem. Although the benefits of regular PA have been recognized and well-documented, only a minor percentage of patients are advised by their doctors or physiotherapists to increase their PA level $[15,16,21]$. The results 
Tab. II. Demographic and physical activity information

\begin{tabular}{|c|c|c|}
\hline Variables & $n$ & Percent \\
\hline \multicolumn{3}{|l|}{ Age (years) } \\
\hline$\leq 50$ & 165 & 49.11 \\
\hline$>50$ & 171 & 50.89 \\
\hline \multicolumn{3}{|l|}{ Body mass index } \\
\hline Normal body mass & 170 & 50.6 \\
\hline Overweight & 147 & 43.75 \\
\hline Obese & 19 & 5.65 \\
\hline \multicolumn{3}{|l|}{ Material status } \\
\hline Bad & 5 & 1.49 \\
\hline Average & 70 & 20.83 \\
\hline Good & 133 & 39.1 \\
\hline Very good & 128 & 38.1 \\
\hline \multicolumn{3}{|l|}{ Education } \\
\hline Elementary & 57 & 16.96 \\
\hline Secondary & 148 & 44.05 \\
\hline Bachelor's degree or higher & 131 & 38.99 \\
\hline \multicolumn{3}{|l|}{ Marital status } \\
\hline Married/with partner & 299 & 88.99 \\
\hline Without partner & 37 & 11.01 \\
\hline \multicolumn{3}{|l|}{ Place of living (population) } \\
\hline$\leq 100000$ & 86 & 25.6 \\
\hline $100000<x \leq 500000$ & 249 & 74.11 \\
\hline$>500000$ & 1 & 0.3 \\
\hline \multicolumn{3}{|l|}{ PA level - work domain } \\
\hline Low & 105 & 31.25 \\
\hline Moderate & 146 & 43.45 \\
\hline Vigorous & 85 & 25.3 \\
\hline \multicolumn{3}{|l|}{ PA level - transportation domain } \\
\hline Low & 159 & 47,32 \\
\hline Moderate & 177 & 52.68 \\
\hline Vigorous & 0 & 0 \\
\hline \multicolumn{3}{|c|}{ PA level - domestic and gardening domain } \\
\hline Low & 85 & 25.3 \\
\hline Moderate & 173 & 51.49 \\
\hline Vigorous & 78 & 23.21 \\
\hline \multicolumn{3}{|l|}{ PA level - leisure time domain } \\
\hline Low & 120 & 35.71 \\
\hline Moderate & 149 & 44.35 \\
\hline Vigorous & 67 & 19.94 \\
\hline
\end{tabular}

PA - physical activity of the 1999-2000 National Health and Nutrition Examination Survey (NHANES) show that approximately 64\% of Americans aged 20 or over are overweight or obese. Between 1980 and 2000, obesity among adult Americans doubled, rising from 15\% to 31\% [23]. The Spanish Association of Gynecology and Obstetrics (2000) indicated that the QoL in perimenopausal females can be significantly improved not only by means of hormone therapy, but also through appropriate diet and regular PA [24].

Research has shown that habitual PA contributes to menopausal women's overall health [25]. Colpani et al. proved that habitual PA, such as walking 6,000 steps per day, reduced the risk of CVD and diabetes in menopausal women [26]. Lara et al. concluded that habitual $\mathrm{PA}$ is a key factor in preserving a favorable cardiovascular profile in menopausal women using HRT [27]. A 6-week regular exercise program was shown to improve the QoL in perimenopausal women. Furthermore, in a study conducted on postmenopausal women who did not use HT or used HT for less than 5 years, the risk of breast cancer decreased in line with the improvement of QoL and a higher PA level [14].

The results of our study showed that most of the respondents presented a moderate level of PA in all domains. This concurred with the results of other studies, which demonstrated that perimenopausal women are more likely to undertake moderate PA [28]. Many women attribute their low PA level to limited free time. However, our study showed that over $50 \%$ of females declared moderate PA while doing housework. Therefore it is important to analyze women's PA in different domains and encourage them to be more active not only in their leisure time, but also while performing every-day activities. Women who do not spend leisure time actively should introduce 'get-moving' strategies at work, during transportation and at home to improve their health and prevent obesity. Skrzypulec et al. indicated that moderate PA reduces climacteric symptoms in menopausal women [13]. Moreover, midlife women who undertook moderate PA for 60 minutes every day were shown to have better QoL [28].

Most women gradually gain weight during the menopause. Physical activity helps to maintain body mass. Women with normal BMI or overweight menopausal women who lost weight had better QoL and fewer climacteric symptoms than females with higher BMI or those who gained weight (particularly if they gained over $5 \mathrm{~kg}$ ) [29]. In our study, BMI was significantly correlated with the PA level. In most women, a moderate PA level was sufficient to have normal BMI; none of the obese women showed a high PA level.

Research shows that three in four menopausal women are overweight or obese [12]. In our study, approximately $44 \%$ of women had normal BMI. Moderate PA levels in the transportation, domestic and leisure time 
Tab. III. Effect of physical activity on body mass index (BMI) in participants $(n=336)$

\begin{tabular}{|c|c|c|c|c|c|c|c|c|}
\hline \multirow[t]{2}{*}{ Physical Activity Domain } & \multicolumn{2}{|c|}{$\begin{array}{c}\text { Normal body mass } \\
<25.0\end{array}$} & \multicolumn{2}{|c|}{$\begin{array}{c}\text { Overweight } \\
25.0 \leq x<30.0\end{array}$} & \multicolumn{2}{|c|}{$\begin{array}{l}\text { Obese } \\
\geq 30.0\end{array}$} & \multirow[t]{2}{*}{$\begin{array}{c}\text { Total } \\
(n)\end{array}$} & \multirow[t]{2}{*}{$p$ value } \\
\hline & $n$ & $\%$ & $n$ & $\%$ & $n$ & $\%$ & & \\
\hline \multicolumn{9}{|l|}{ Work Domain } \\
\hline Low & 28 & 8.34 & 62 & 18.45 & 15 & 4.46 & 105 & \multirow{3}{*}{$<0.01$} \\
\hline Moderate & 73 & 21.73 & 69 & 20.53 & 4 & 1.19 & 146 & \\
\hline High & 69 & 20.54 & 16 & 4.76 & 0 & 0 & 85 & \\
\hline Total $(n)$ & 170 & & 147 & & 19 & & & \\
\hline \multicolumn{9}{|c|}{ Active Transportation Domain } \\
\hline Low & 63 & 18.75 & 82 & 24.4 & 14 & 4.17 & 159 & \multirow{2}{*}{$<0.01$} \\
\hline Moderate & 107 & 31.84 & 65 & 19.35 & 5 & 1.49 & 177 & \\
\hline Total $(n)$ & 170 & & 147 & & 19 & & & \\
\hline \multicolumn{9}{|c|}{ Domestic and Garden [Yard Work] Domain } \\
\hline Low & 46 & 13.69 & 28 & 8.33 & 11 & 3.28 & 85 & \multirow{3}{*}{$<0.01$} \\
\hline Moderate & 76 & 22.61 & 89 & 26.5 & 8 & 2.38 & 173 & \\
\hline High & 48 & 14.19 & 30 & 8.92 & 0 & 0 & 78 & \\
\hline Total $(n)$ & 170 & & 147 & & 19 & & & \\
\hline \multicolumn{9}{|l|}{ Leisure-Time Domain } \\
\hline Low & 50 & 14.88 & 56 & 16.66 & 14 & 4.17 & 120 & \multirow{3}{*}{$<0.01$} \\
\hline Moderate & 74 & 22.02 & 70 & 20.84 & 5 & 1.49 & 149 & \\
\hline High & 46 & 13.69 & 21 & 6.25 & 0 & 0 & 67 & \\
\hline Total $(n)$ & 170 & & 147 & & 19 & & & \\
\hline
\end{tabular}

domains appear to be sufficient for most climacteric women to maintain normal BMI. Our study has shown that obese women lead a sedentary lifestyle and present a low PA level in all domains. This suggests that menopausal women should be informed that PA does not have to be limited to leisure time only; they should be advised how to improve their health, reduce body mass and prevent obesity while performing every-day activities.

There are many ways to reduce body mass, ranging from calorie-reduced diet and PA to pharmacotherapy and surgery. A recent study has shown that PA has a profound effect on obesity and fat distribution [30]. Walking, both as a means of transport and a leisuretime activity, is a form of PA which positively affects the mood [31]. It does not require a financial investment or joining a fitness club, it is not too strenuous, and is easy to start. Perimenopausal women should take regular walks in order to improve their QoL.

The direct correlation between obesity and fatal cardiovascular disease is the strongest in women with very high intra-abdominal fat [2]. Sjorstrom et al. showed a correlation between excess abdominal fat and chronic disease risk across a wide range of $\mathrm{BMI}$ [31]. In our study, a relationship between PA and BMI was observed: physically active women in each domain had a lower BMI, which means that PA reduces BMI in menopausal women. In our study, there were no obese women with a high PA level in any domain. The highest number of women with a high PA level was found among respondents with normal body mass. In the moderate PA level group, only few women were obese. This suggests that moderate PA is not sufficient to eliminate obesity completely, but may help maintain current body weight. Other studies have shown that maintaining normal body mass requires 60 minutes of moderate PA per day. Maintaining normal weight is also important for good physical functioning. Hence, PA should be encouraged regardless of weight [32].

Tab. IV. Pearson correlation, $p$ value and correlation value $r$ between demographic factors and body mass index

\begin{tabular}{lcc}
\hline Variables & $\begin{array}{c}\text { Correlation } \\
\text { value } r\end{array}$ & $p$ value \\
\hline Age (years) & 0.5951 & $<0.01$ \\
\hline Material status & -0.691 & 0.07 \\
\hline Education & -0.2686 & $<0.01$ \\
\hline Marital status & 0.0976 & 0.074 \\
\hline Place of living (population) & 0.0988 & 0.07 \\
\hline PA level - work domain & -0.5788 & $<0.01$ \\
\hline $\begin{array}{l}\text { PA level - transportation } \\
\text { domain }\end{array}$ & -0.2319 & $<0.01$ \\
\hline $\begin{array}{l}\text { PA level - domestic } \\
\text { and gardening domain }\end{array}$ & -0.4057 & $<0.01$ \\
\hline $\begin{array}{l}\text { PA level - leisure time domain } \\
\text { PA }- \text { physical activity }\end{array}$ & -0.5175 & $<0.01$ \\
\hline
\end{tabular}

PA - physical activity 
In summary, the menopausal transition is often accompanied by body mass gain, particularly in the form of abdominal fat, which can increase the risk of many severe and fatal diseases. Thus, all health care professionals should help their patients prevent obesity. Women should be advised how to maintain normal BMI and, if necessary, be informed on weight-loss methods. Numerous studies suggest that menopausal women should undertake two strength training sessions per week, regular aerobic exercises, or 60 minutes of moderate PA per day in order to maintain normal body mass [2]. Our findings show that women may undertake PA not only in their free-time, but also during every-day activities, such as commuting to work, housework or gardening. There were no obese women among high PA respondents, whilst most women with moderate PA levels were either overweight or had normal body mass. Therefore, all health care professionals should encourage perimenopausal women to remain active not only in their leisure time.

The main strengths of the study were the size of the sample and the use of the recommended IPAQ long format, which enabled us to assess PA levels in different domains. Our study adds value to the research on the relation between PA and obesity in menopausal females by showing that women can be active not only in their free time, but also while performing every-day activities. Further research is required to assess the impact of this type of PA in different domains on women's health and to formulate suitable guidelines on PA for all menopausal women, including those who are not active and who do not have the time to exercise in their leisure time. Such guidelines would enable physicians and/or physiotherapists to advise their patients on the PA required to maintain normal body mass and to improve their general health and well-being. This study is limited to a cross sectional analysis.

\section{Conclusions}

This study examined the PA levels of climacteric women in different domains. The general PA level was satisfactory. Most respondents presented moderate PA levels in all domains except work, where the PA levels were high.

Sedentary lifestyle and low PA levels, particularly during menopausal transition, may result in obesity and severe health problems. The results of our study show that menopausal women can manage their body mass and improve their health by changing their lifestyle and performing moderate PA in every-day tasks. The level of PA correlated with BMI in all domains. Particularly strong correlations were shown in the work and leisure time domains. A limitation of the study is the fact that $\mathrm{BMI}$ was based on the data provided by the respondents. The study is going to be continued with additional factors such as diet, hormonal status and body composition. Height and body mass are going to be assessed by the researcher so as to make the data more reliable.

\section{Acknowledgements}

We wish to acknowledge the help of all the women who kindly agreed to take part in this research.

This research was not supported by any grant.

\section{Disclosure}

Authors report no conflict of interest.

\section{References}

1. Warburton DE, Nicol CW, Bredin SS. Health benefits of physical activity: the evidence. CMAJ 2006; 174: 801-809.

2. Fogelholm M, Stallkecht B, van Baak M. ECSS position statement: exercise and obesity. Eur J Sport Sci 2006; 6: 15-24.

3. World Health Organization (WHO) Global Recommendations on Physical Activity for Health. WHO, Geneva 2010.

4. Skrzypulec V, Naworska B, Drosdzol A. Analiza wpływu objawów klimakterycznych na funkcjonowanie i jakość życia kobiet w okresie okołomenopauzalnym. Prz Menopauzalny 2007; 6: 96-101.

5. Moilanen JM, Aalto AM, Raitanen J, et al. Physical activity and changes in quality of life during menopause - an 8-year follow up study. Health Qual Life Outcomes 2012; 10: 8-14.

6. Skrzyplec V, Drosdzol A, Kowalczyk R, et al. Problemy seksualne kobiet w okresie klimakterium w praktyce klinicznej. Prz Menopauzalny 2004; 3: 16-23.

7. Skrzypulec-Plinta V, Chełmicki A, Gojdź K. Czy spadek libido po menopauzie ma podłoże hormonalne? Prz Menopauzalny 2011; 10: 334-337.

8. Miller AM, Wilbur J, Chandler PJ, Sorokin O. Cardiovascular risk factors and menopausal status in midlife women from the former Soviet Union. Women Health 2003; 38: 19-36.

9. European cardiovascular disease statistics 2008 edition; http://www. herzstiftung.ch/uploads/media/European_cardiovascular_disease_statistics_2008.pdf. Accessed December 21, 2012

10. Centers for Disease Control and Prevention; http://www.cdc.gov/dh$\mathrm{dsp} /$ data statistics/fact sheets/fs women heart.htm, Kochanek KD, Xu JQ, Murphy SL, Miniño AM, Kung HC. Death: final data for 2009. National vital statistics reports,2011;60(3). Accessed November 9, 2012.

11. Pertyński T, Stachowiak G, Stetkiewicz T. Rola ginekologa w okresie prei okołomenopauzalnym. Prz Menopauzalny 2007; 6: 63-69.

12. Bąk-Sosnowska M, Skrzypulec-Plinta V. Przyczyny nadmiernej masy ciała u kobiet w okresie menopauzalnym. Prz Menopauzalny 2012; 11: 31-35.

13. Skrzypulec V, Dąbrowska J, Drosdzol A. The influence of physical activity level on climacteric symptoms in menopausal women. Climacteric 2010; 13: 355-361.

14. Irwin ML, McTiernan A, Manson JE, et al. Physical activity and survival in postmenopausal women with breast cancer: results from the women's health initiative. Cancer Prev Res (Phila) 2011; 4: 522-529.

15. http://www.acsm.org/about-acsm/media-room/acsm-in-the-news/ 2011/08/01/acsm-aha-support-federal-physical-activity-guidelines, 20 September 2014.

16. Dąbrowska J, Drosdzol A, Skrzypulec V, Plinta R. Physical activity and sexuality in perimenopausal women. Eur J Contracept Reprod Health Care 2010; 15: 423-432

17. Asbury EA, Chandrruangphen P, Collins P. The importance of continued exercise participation in quality of life and psychological well-being in previous inactive postmenopausal women: a pilot study. Menopause 2006; 13: 561-567.

18. Jurakić D, Pedisic Z, Greblo Z. Physical activity in different domains and health-related quality of life: a population-based study. Qual Life Res 2010; 19: 1303-1309. 
19. Hallal PC, Gomez LF, Parra DC, et al. Lessons learned after 10 years of IPAQ use in Brazil and Columbia. J Phys Act Health 2010; 7: 259-264.

20. www.ipaq.ki.se. Accessed: December 16, 2012

21. Dąbrowska-Galas M, Plinta R, Dąbrowska J, Skrzypulec-Plinta V. Physical activity in students of the Medical University of Silesia in Poland. Phys Ther 2013; 93: 384-392.

22. http://apps.who.int/bmi/index.jsp?introPage=intro_3.html. Accessed: October 12, 2014

23. http://www.cdc.gov/healthyplaces/healthtopics/physactivity.htm Accessed: December 16, 2012

24. Bosch X. Spain focuses on quality of life during menopause. Lancet 2000; 355: 478

25. Kemmler W, von Stengel S, Weinck J, et al. Exercise effects on menopausal risk factor of early postmenopausal women: 3-yr Erlangen fitness osteoporosis prevention study results. Med Sci Sports Exerc 2005; 37 194-203.

26. Colpani V, Opermann K, Spritz PM. Association between habitual physical activity and lower cardiovascular risk in premenopausal, perimenopausal, and postmenopausalwomen: a population-based study. Menopause 2013; 20: 525-531.
27. Lara S, Casanova G, Spritzer PM. Influence of habitual physical activity on body composition, fat distribution and metabolic variables an early postmenopausal women receiving hormonal therapy. Eur J Obstet Gynecol Reprod Biol 2010; 150: 52-56.

28. Guimaraes AC, Baptista F. Influence of habitual physical activity on the symptoms of climacterium/menopause and the quality of life of middle-aged women. Int J Womens Health 2011; 3: 319-328.

29. Fontaine KR, Barofsky I, Andersen RE, et al. Impact of weight loss on health-related quality of life. Qual Life Res 1999; 8: 275-277.

30. Valadares AL, Carvalho ED, Costa-Paiva LH, et al. Association between different types of physical activities and quality of life in women aged 60 years or over. Rev Assoc Med Bras 2011; 57: 450-455.

31. Sjostrom CD, Lissner L, Sjostrom L. Relationship between changes in body composition and changes in cardiovascular risk factors: the SOS Intervention Study. Swedish Obese Subjects. Obes Res 1997; 5: 519-530.

32. Lindhom V, Lahti J, Rahkonen $\mathrm{O}$, et al. Joint association of physical activity and body weight with subsequent physical and mental functioning: a follow-up study. BMC Public Health 2013; 13: 197-205. 